
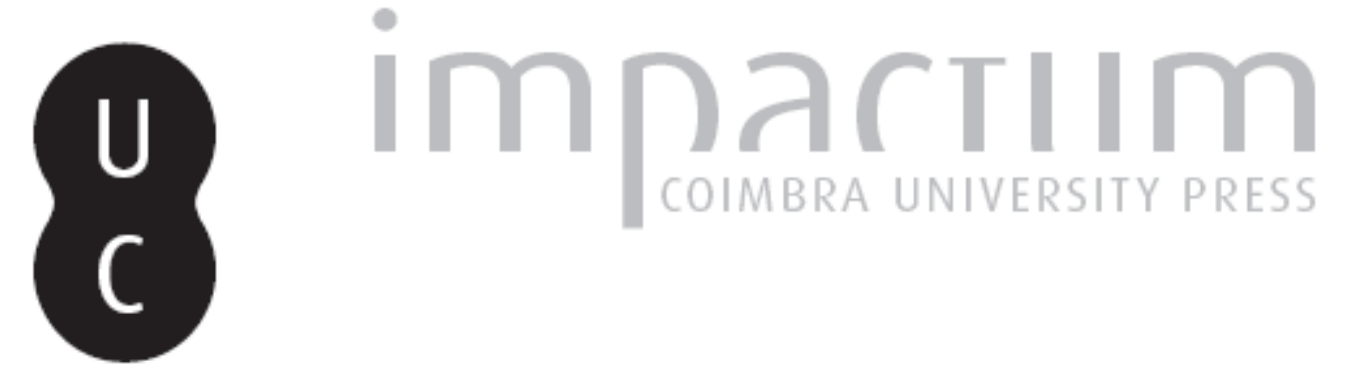

\title{
As instituições divinas de Lactâncio e sua relação com o epítome
}

Autor(es): $\quad$ Abrantes, Miguel Rúben F. C.

Publicado por: Imprensa da Universidade de Coimbra

URL persistente:

URI:http://hdl.handle.net/10316.2/41469

DOI:

DOI:https://doi.org/10.14195/0872-2110_60_7

Accessed : $\quad$ 26-Apr-2023 14:48:27

A navegação consulta e descarregamento dos títulos inseridos nas Bibliotecas Digitais UC Digitalis, UC Pombalina e UC Impactum, pressupõem a aceitação plena e sem reservas dos Termos e Condições de Uso destas Bibliotecas Digitais, disponíveis em https://digitalis.uc.pt/pt-pt/termos.

Conforme exposto nos referidos Termos e Condições de Uso, o descarregamento de títulos de acesso restrito requer uma licença válida de autorização devendo o utilizador aceder ao(s) documento(s) a partir de um endereço de IP da instituição detentora da supramencionada licença.

Ao utilizador é apenas permitido o descarregamento para uso pessoal, pelo que o emprego do(s) título(s) descarregado(s) para outro fim, designadamente comercial, carece de autorização do respetivo autor ou editor da obra.

Na medida em que todas as obras da UC Digitalis se encontram protegidas pelo Código do Direito de Autor e Direitos Conexos e demais legislação aplicável, toda a cópia, parcial ou total, deste documento, nos casos em que é legalmente admitida, deverá conter ou fazer-se acompanhar por este aviso.

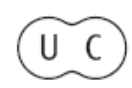


COIMBRA • 2015

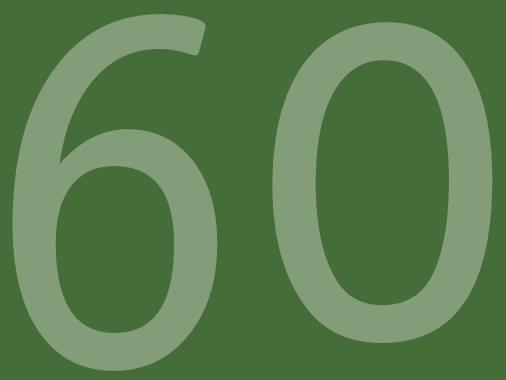

\title{
BOLETIM DE
}

\section{ESTUDOS CLÁSSICOS}

\author{
ASSOCIAÇÃO \\ PORTUGUESA \\ DE ESTUDOS \\ CLÁSSICOS \\ INSTITUTO \\ DE ESTUDOS \\ CLÁSSICOS
}




\title{
AS INSTITUIÇÕES DIVINAS DE LACTÂNCIO E SUA RELAÇÃO COM O EPÍTOME
}

\section{LACTANTIUS' DIVINE INSTITUTES AND ITS RELATIONSHIP WITH THE EPITOME}

\author{
MIGUEL RÚBEN F. C. ABRANTES \\ MESTRE EM ESTUDOS CLÁSSICOS - UNIVERSIDADE DE COIMBRA \\ miguel.r.abrantes@gmail.com
}

Resumo: Se o epítome de uma obra deverá, idealmente, reter todos os conteúdos mais importantes do original, esse processo também implica uma sinopse de ideias com base num objectivo particular. As Instituições Divinas e o Epítome da mesma obra, ambos da autoria indisputada de Lactâncio, permitem-nos constatar a forma como um autor simplifica o seu texto, adaptando-o, como iremos argumentar, com base na audiência final e acabando por produzir uma obra que, apesar do seu título, não se trata de simples resumo.

Palavras-chave: Lactâncio; apologia cristã; Instituições Divinas.

Abstract: If the epitome of a work should ideally retain all the most important content of the original, this process should also imply a synopsis of ideas based on a particular goal. The Divine Institutes and the Epitome of the same work, both indisputably authored by Lactantius, allow us to note the way in which an author simplifies his text, adapting it, as we will argue, based on the final audience and eventually producing a work that, in spite of its title, is not a simple resume.

Keywords: Lactantius; Christian apologetics; Divine Institutes. 


\section{AS INSTITUIÇÕES DIVINAS DE LACTÂNCIO E SUA RELAÇÃO COM O EPITOME ${ }^{1}$}

Quando no início do século IV d.C. a actividade literária de Lactâncio surge, fá-lo num contexto cultural e religioso muito específico. Com a conversão do imperador Constantino, o cristianismo deixa de ser tanto uma religião do povo para começar a ser visto cada vez mais também como uma religião das elites, que a ela terão de aderir se quiserem manter a sua posição social. É nesse contexto que surgem as Instituições Divinas, em sete livros, cujo principal objectivo era o de simultaneamente apontar e refutar os erros do Paganismo ${ }^{2}$, mas também exaltar todos os benefícios da nova religião. A ideia não era nova, já a Epístola a Diogneto ou autores como Novaciano dela tinham tratado e a ela voltarão mais tarde autores como Santo Agostinho e Orósio. Porém, poucos serão aqueles que o conseguiram fazer de forma tão sublime como Lactâncio, algo que lhe valeu, muitos séculos mais tarde, o título de "Cícero Cristão".

Se Santo Agostinho viria a trabalhar este tema na sua Cidade de Deus, se Orósio o fez nas Histórias contra os Pagãos e se tantos outros o fizeram ao longo dos séculos, um aspecto de especial importância no caso de Lactâncio é o facto de este ter trabalhado o tema essencial não num único texto, as Instituições Divinas, mas em dois, sendo o segundo um epítome do primeiro, escrito a pedido de um irmão, Pentádio. No prefácio, o próprio autor admite a dificuldade de tratar numa só obra "aquilo que foi tratado em sete grandes volumes" (Epit. Div. Inst., prefácio), mas, ironicamente, acaba por ser o fruto dessa dificuldade que nos permite agora ter uma oportunidade única de constatar, pela mão

${ }^{1}$ À escrita destas linhas devo associar um enorme agradecimento à Professora Doutora Nair Castro Soares, por todos os seus ensinamentos e por me ter conduzido ao estudo do tema aqui apresentado.

2 "Paganismo", "Pagão" e expressões similares são usadas neste documento com sentido não pejorativo e apenas para designar o conjunto de religiões que então se opunham ao cristianismo. 
de um mesmo autor ${ }^{3}$, tudo aquilo que deve ser considerado essencial na mais famosa das suas obras.

Partindo do Epítome e estabelecendo uma comparação com as Instituições Divinas, podemos extrair os ensinamentos fundamentais de Lactâncio, mas também avaliar se em algum ponto aquilo que consideramos essencial era, afinal, visto da mesma forma pelo próprio autor, ou se este acaba por considerar alguns desses elementos como secundários. Compare-se, portanto, o esquema temático das duas obras, atentando às semelhanças e divergências entre ambas, para que possamos melhor analisar esses elementos fulcrais.

Nos capítulos iniciais do epítome o autor começa por demostrar muito sucintamente que existe uma divina Providência, "já que o mundo não poderia existir sem um senhor", algo que Epicuro parecia negar ${ }^{4}$. Das autoridades aí mencionadas, importa frisar a ausência de Cícero ${ }^{5}$, de especial importância, visto que ao longo de toda a obra este autor, bem como as suas várias criações, parecem estar sempre presentes. Nos capítulos seguintes, é demonstrado que só poderá existir um único deus, que vários são os autores dessa opinião e que esse único deus não só não tem corpo, como não necessita de procriar ${ }^{6}$. Para chegar a essa conclusão, recorrem-se a testemunhos de poetas e de filósofos, sendo precisamente aqui que se nota a primeira das diferenças entre as duas obras - no Epítome, o autor não só dá menos relevância aos testemunhos provindos dos deuses ${ }^{7}$, como também omite muitas das citações que faz e que apoiam as suas ideias.

${ }^{3}$ Perrin 1986: 40.

${ }^{4}$ Epit. Div. Inst. 1.

${ }^{5} \mathrm{Cf}$. Div. Inst. 1.2, onde Cícero é mencionado pela primeira vez.

${ }^{6}$ Div. Inst. 1.3-8, Epit. Div. Inst. 2-6.

${ }^{7}$ Cf. Div. Inst. 1.8, em que o autor menciona vários testemunhos oraculares que apoiavam a sua tese. É provável, mas não certo, que esses extratos tenham provindo da Filosofia dos Oráculos de Porfírio. 
Nos capítulos seguintes, apela a um argumento sempre presente nas obras contra as religiões pagãs - a imoralidade dos vários deuses, sejam eles Hércules, Esculápio ou Júpiter, apenas para mencionar alguns. Demonstra que esses deuses eram mortais deificados, recorrendo ao testemunho de Evémero ${ }^{8}$, autor cujas ideias ${ }^{9}$ estão sempre presentes nas obras de apologia ao cristianismo. Aqui se nota, novamente, uma importante diferença entre ambas as obras - se no caso do Epitome o tratamento deste tema é bastante sintético, já na sua maior obra Lactâncio prolonga a discussão por várias páginas, ocupando-se também de várias opiniões filosóficas e da impossibilidade de venerar esses deuses juntamente com o verdadeiro Deus, entre outros temas que parece considerar importantes. Depois descreve os rituais religiosos dos romanos e dos outros povos, frisando quem os teria inventado e por que razão, mostrando que esses ritos tinham origem humana, mais do que divina, momento em que termina o primeiro livro das Instituições Divinas, bem como o capítulo 23 do Epítome.

O segundo livro da obra trata das origens do erro de que sofriam as religiões pagãs, com os Homens a serem apresentados como criadores da veneração religiosa apenas para benefício próprio ${ }^{10}$, como no caso de um rei Júpiter que, segundo Evémero, teria ordenado a criação de vários templos e festivais em sua própria honra. Explicita a construção dos primeiros ídolos, nascidos da necessidade humana de recordar os que já faleceram, mas refere igualmente que se esses deuses fossem omnipresentes ${ }^{11}$, as suas imagens jamais seriam necessárias. Menciona ainda a importância dos humanos como anthropos ${ }^{12}$, os únicos seres que

\footnotetext{
${ }^{8}$ Div. Inst. 1.11, 1.14; Epit. Div. Inst. 13.

${ }^{9}$ Em particular a tese de que os antigos deuses eram mortais deificados.

${ }^{10}$ Epit. Div. Inst. 24.

${ }^{11}$ Uma característica divina que pode ser concluída dos textos de quase todos os autores pagãos.

${ }^{12}$ Uma (suposta) derivação da palavra levaria o leitor a pensar na singular capacidade de virar a cabeça para cima. Se este é um argumento importante para Lactâncio, que o repete várias vezes ao longo de toda a sua obra, não é partilhado com outros
} 
caminhavam erectos, ou seja, que conseguiam fitar os céus e a presença de quem os tinha criado ${ }^{13}$. Sucedem-se evidências de que Cícero e Lucrécio já sabiam que os deuses que veneravam eram falsos ${ }^{14}$, mas que ainda assim nada fizeram para evitar que outros homens caíssem no mesmo erro - um importante detalhe que o autor omite no Epítome.

É neste momento que o trajecto de ambas as obras se começa a afastar. Até aqui ambas seguiam quase precisamente o mesmo caminho, limitando-se o autor a suprimir vários exemplos e a omitir muitas das suas citações, mas se o Epitome fala apenas da veneração dos elementos e das estrelas ${ }^{15}$, na outra obra o autor continua a sua ideia-base, refutando ideias dos estoicos ${ }^{16}$ e outras concepções religiosas ${ }^{17}$ antes de se concentrar nos portentos das religiões pagã ${ }^{18}$. Para os justificar o autor conta toda a história da criação do Homem e dos animais ${ }^{19}$, apresentando os daemon como anjos cristãos caídos por influência do diabolos. Os portentos são então justificados como tendo origem nos daemones ${ }^{20}$, sendo que Deus apenas permitiria essa sua influência devido à necessidade de separar quem é bom de quem é mau, de forma a que se pudesse "coroar o vitorioso com a recompensa da imortalidade"21. Aqui termina o segundo livro das Instituições Divinas e o capítulo 29 do Epítome.

autores e deve ser comparado, por exemplo, com o argumento patente no $36^{\circ}$ discurso de Dion Crisóstomos.

${ }^{13}$ Div. Inst. 2.1, Epit. Div. Inst. 25.

${ }^{14}$ Div. Inst. 2.3.

${ }^{15}$ Epit. Div. Inst. 26.

${ }^{16}$ Div. Inst. 2.5.

${ }^{17}$ Div. Inst. 2.6.

${ }^{18}$ Div. Inst. 2.8.

${ }^{19}$ Div. Inst. 2.9-15, Epit. Div. Inst. 27.

${ }^{20}$ Div. Inst. 2.17, Epit. Div. Inst. 28.

${ }^{21}$ Epit. Div. Inst. 29. 
O terceiro livro das Instituições Divinas pretende tratar da falsa sabedoria dos filósofos ${ }^{22}$. Estes são apresentados como tendo uma tarefa vã, em que toda uma vida não bastaria para atingir a sabedoria que procuravam ${ }^{23}$, passando o seu trabalho somente pelo conhecimento e pela conjectura ${ }^{24}$, tendo a impossibilidade do primeiro objectivo sido provada por Sócrates e a do segundo por Zenão ${ }^{25}$. É mostrada a confusão vigente entre as diversas seitas filosóficas, partindo o autor em busca do bem maior da verdadeira sabedoria ${ }^{26}$, que deveria ser exclusiva ao Homem, pertencer apenas à alma e que não poderia ser de alguém que não tivesse conhecimento ou virtude ${ }^{27}$. $O$ autor acaba por concluir que esse "bem maior" era a imortalidade ${ }^{28}$.

Começando com os exemplos de Cícero, Lucrécio e Séneca, todos eles omitidos no Epítome, o autor demonstra os erros de cada autor e a impossibilidade de se seguir os preceitos por eles estipulados ${ }^{29}$, já que nem os próprios o conseguiam fazer. Erros semelhantes são apontados a filósofos como Epicuro, Pitágoras, Sócrates e Platão ${ }^{30}$, tanto a nível das suas ideologias gerais como de várias ideias que defendiam ${ }^{31}$, sendo a verdadeira sabedoria proclamada novamente como aquela que vem,

\footnotetext{
${ }^{22}$ Esta é uma ideia que parece já vir dos textos de São Paulo, que na Primeira Epístola aos Coríntios opunha a sabedoria do mundo (i.e. dos filósofos) à sabedoria divina, sendo esta segunda sempre apresentada como muito superior à primeira por provir directamente de Deus.

${ }^{23}$ Div. Inst. 3.1-2, Epit. Div. Inst. 30.

${ }^{24}$ Div. Inst. 3.3, Epit. Div. Inst. 31.

${ }^{25}$ Div. Inst. 3.4, Epit. Div. Inst. 31.

${ }^{26}$ Div. Inst. 3.7-9, Epit. Div. Inst. 33-35.

${ }^{27}$ Div. Inst. 3.9.

${ }^{28}$ Div. Inst. 3.11, Epit. Div. Inst. 35.

${ }^{29}$ Div. Inst. 3.16.

${ }^{30}$ Div. Inst. 3.17-23, Epit. Div. Inst. 36-39.

${ }^{31}$ Div. Inst. 3.24-25, Epit. Div. Inst. 40.
} 
em exclusivo, do verdadeiro Deus ${ }^{32}$. Assim termina o terceiro livro das Instituições Divinas e o capítulo 41 do Epítome.

Após ter refutado os vários erros do Paganismo, o autor passa agora à sua apologia do cristianismo, tarefa que empreende nas restantes páginas de ambas as obras. Começa por demonstrar como são a verdadeira sabedoria e religião. Também aqui o autor deixa muito material de fora do Epitome, especificamente alguns temas que ainda vinham do livro anterior $^{33}$. Apesar de fazer algumas vagas alusões aos temas tratados, só retoma o tema principal já no capítulo 7 do quarto livro das Instituições Divinas, em que refere a impossibilidade de se saber o verdadeiro nome de Jesus Cristo ${ }^{34}$, que "nem é conhecido pelos anjos que estão no céu" ${ }^{35}$. A dupla natureza e dupla natividade de Cristo são vistas como necessárias, para que ele pudesse sentir o sofrimento da carne, sendo vários os episódios da vida de Jesus que o autor refere como tendo sido profetizados por figuras do passado.

É nesse tema que o autor ocupa o resto do quarto livro ${ }^{36}$, mencionando sucessivamente os vários episódios da vida de Cristo, sejam eles de âmbito físico ou sobrenatural, apoiando cada um desses eventos com múltiplas citações dos Evangelhos, de livros do Antigo Testamento e dos testemunhos das várias Sibilas, para mostrar que eles já tinham sido previstos muito antes da vinda de Cristo. Nesses vários capítulos a principal diferença entre as duas obras prende-se com o número de citações e extensão das mesmas. Porém, no derradeiro capítulo 30 do quarto livro, o autor faz referência a algumas heresias que não conduziam à salvação, ideia que está totalmente ausente do Epitome.

\footnotetext{
${ }^{32}$ Div. Inst. 3.26-30, Epit. Div. Inst. 41.

${ }^{33}$ Por exemplo, o porquê de Pítagoras e Platão não terem atingido a verdadeira sabedoria.

${ }^{34}$ Sendo aqui o seu famoso nome interpretado como "Rei Salvador".

${ }^{35}$ Div. Inst. 4.7.

${ }^{36}$ Cf. Epit. Div. Inst. 43-55.
} 
O quinto livro das Instituições Divinas, cujo tema também começa no capítulo 56 do Epítome, trata da Justiça, aqui definida como uma veneração do verdadeiro Deus. É neste momento que surge uma enorme discrepância entre o conteúdo das duas obras, já que 24 capítulos da obra original são resumidos em somente dois do Epitome. Desta forma, se o segundo texto aborda somente a importância da justiça e a sabedoria dos Cristãos como provinda de Deus ${ }^{37}$, que lhes dará a devida recompensa na melhor altura, já a obra principal aborda temas como o facto de Jesus não ter sido um feiticeiro ${ }^{38}$, contrastando-o com as figuras de Apuleio e de Apolónio de Tiana ${ }^{39}$, a decadência da justiça após o reinado de Saturno ${ }^{40}$ ou as torturas aos Cristãos $^{41}$, bem como a crueldade dos Pagãos ${ }^{42}$ e a vingança divina a que seriam sujeitos todos aqueles que perseguiam os seguidores da nova religião $0^{43}$.

O sexto livro da obra, cuja temática principia no capítulo 58 do Epitome, fala da veneração do verdadeiro Deus. É dito que esse Deus, contrariamente aos deuses pagãos, não necessitava de bens terrenos nem de sacrifícios deles provenientes ${ }^{44}$. São apontados dois possíveis caminhos na vida, "um que leva ao céu, e um outro que afunda para o Inferno" ${ }^{45}$, tema que as Instituições Divinas abordam de uma forma mais

${ }^{37}$ Epit. Div. Inst. 56-57.

${ }^{38}$ Div. Inst. 5.3.

${ }^{39}$ Recorde-se que o primeiro, autor do Burro de Ouro, foi acusado de ser um mago, acusação de que se defende na sua Apologia. Já o segundo, cujos feitos nos chegam numa biografia de Filóstrato (que, importa frisar, só foi escrita muito após o desaparecimento de Apolónio), é sempre mencionado neste contexto, com a semelhança entre esta figura e Jesus, hoje difícil de perceber, a ser repetida por vários defensores do Paganismo.

${ }^{40}$ Div. Inst. 5.5.

${ }^{41}$ Div. Inst. 5.9.

${ }^{42}$ Div. Inst. 5.11.

${ }^{43}$ Div. Inst. 5.24. Um tema que Lactâncio também aborda numa outra obra, A Morte dos Perseguidores.

${ }^{44}$ Div. Inst. 6.1-2, Epit. Div. Inst. 58.

${ }^{45}$ Div. Inst. 6.3 . 
extensa ${ }^{46}$. Um pouco mais à frente ambos os textos retomam um mesmo tema com a referência às "três Fúrias" ${ }^{47}$ - cólera, amor pelo dinheiro e luxúria - às quais se deveria resistir a todo o custo, falando igualmente da importância de restringir os prazeres dos sentidos nas suas diversas áreas ${ }^{48}$, como seria o caso dos espectáculos ${ }^{49}$ e das várias paixões ${ }^{50}$. Este último tema é mais desenvolvido nas Instituições Divinas, em que o autor nos menciona as paixões dos olhos (como os espectáculos), dos ouvidos ("o que dá prazer aos ouvidos tem persuasão, e enquanto deleita também se fixa profundamente no interior do peito", por oposição à simplicidade das Escrituras ${ }^{51}$ ), do sabor e do cheiro (em que é dito que um homem sábio não deve ser escravo dos seus apetites ${ }^{52}$ ), do prazer e da luxúria (que o autor também opõe à importância do casamento e da continência ${ }^{53}$. Esse mesmo livro termina referindo-se à posição contrária a esses temas, com uma alusão aos ensinamentos que deveriam ser seguidos ${ }^{54} \mathrm{e}$ à forma própria para venerar o verdadeiro Deus ${ }^{55}$.

O último livro das Instituições Divinas, cuja temática também é abordada nos capítulos 68 a 73 do Epítome, procura levar o leitor a uma vida feliz. 0 autor discute a razão porque Deus criou o mundo e o Homem ${ }^{56}$. Referindo-se aos erros dos filósofos, mostra que este é um Deus bom e que, portanto, criou as coisas boas ${ }^{57}$, sendo que o mundo foi criado

\footnotetext{
${ }^{46}$ Div. Inst. 6.4-19.

${ }^{47}$ Div. Inst. 6.19, Epit. Div. Inst. 61.

${ }^{48}$ Div. Inst. 6.20-24, Epit. Div. Inst. 62.

${ }^{49}$ Div. Inst. 6.20, Epit. Div. Inst. 63.

${ }^{50}$ Div. Inst. 6.20-24, Epit. Div. Inst. 64.

${ }^{51}$ Cf. Div. Inst. 6.21.

${ }^{52}$ Cf. Div. Inst. 6.22.

${ }^{53}$ Cf. Div. Inst. 6.23, Epit. Div. Inst. 66.

${ }^{54}$ Div. Inst. 6.24, Epit. Div. Inst. 65-66.

${ }^{55}$ Div. Inst. 6.25, Epit. Div. Inst. 65-67.

${ }^{56}$ Div. Inst. 7.4-6, Epit. Div. Inst. 68.

${ }^{57}$ Div. Inst. 7.4-6, Epit. Div. Inst. 68.
} 
para os Humanos e os Humanos para Deus, para que estes o possam venerar ${ }^{58}$. Sobre o Homem, o autor pergunta-se: "Quem, além do Homem, consegue olhar para os céus? ${ }^{59}$ Quem habita a Terra? Quem recebe os frutos dela? Quem tem em seu poder os peixes, as criaturas voadoras, os quadrúpedes, além do Homem?", concluindo que todas as coisas foram criadas para o Homem, para que este faça uso delas ${ }^{60}$.

Em seguida, o autor foca-se na questão da imortalidade da alma ${ }^{61}$. Para provar essa possibilidade, Lactâncio começa por recorrer aos textos de Platão e de outros filósofos. Através da confessa ignorância de Cícero na matéria ${ }^{62}$, o autor recorre aos "testemunhos divinos"63, que aqui lhe permitem mostrar uma horizontalidade dessa crença, opinião partilhada pelos deuses pagãos, pelos poemas das Sibilas, pelos textos de Hermes Trimegisto e por várias outras fontes, face aos erros ${ }^{64}$ de autores como Demócrito ou Epicuro.

Para terminar a obra o autor aborda o tema do final dos tempos. Começa por descrever tudo aquilo que iria ter lugar nessa altura ${ }^{65}$, antes de narrar o advento de Cristo e os eventos que o sucederiam ${ }^{66}$. Ambas as obras terminam com uma pequena apologia a todos aqueles que seguiam o caminho do verdadeiro Deus, assegurando-lhes que a

\footnotetext{
${ }^{58}$ Div. Inst. 7.6, Epit. Div. Inst. 69.

${ }^{59}$ Este argumento parece ser de especial importância para Lactâncio que, como referido anteriormente, o usa diversas vezes ao longo de toda a sua obra.

${ }^{60}$ Epit. Div. Inst. 69.

${ }^{61}$ Div. Inst. 7.8-10, Epit. Div. Inst. 70.

${ }^{62}$ Div. Inst. 7.8.

${ }^{63}$ Div. Inst. 7.13, Epit. Div. Inst. 70. Esta expressão usada pelo autor múltiplas vezes ao longo de toda a obra pretende referir-se a autoridades como os oráculos dos deuses pagãos e os escritos dos profetas, das Sibilas e de Hermes Trimegisto.

${ }^{64}$ Erros que o autor considera evidentes em virtude do peso dos testemunhos de opinião contrária.

${ }^{65}$ Div. Inst. 7.15-18, Epit. Div. Inst. 71.

${ }^{66}$ Div. Inst. 7.19-26, Epit. Div. Inst. 72.
} 
salvação e a protecção contra os vários eventos que tinha acabado de referir apenas provinha da verdadeira religião, o cristianismo ${ }^{67}$.

Partindo desta sucinta análise das duas obras o que poderemos concluir? À primeira vista poderia parecer-nos que o Epitome é somente um lacónico resumo das Instituições Divinas - de facto, a edição francesa de M. Perrin considera-o como "un abrégé en soixante-huit paragraphes des sept livres des Institutions divines", o que até nos poderia levar, erradamente, a essa ideia - mas a leitura comparada de ambos os textos permite-nos constatar que essa selecção por parte do autor não foi assim tão simples, tendo sido realizada com base num objectivo programático muito específico.

Essa potencial intenção do autor, que o levou a suprimir alguns temas no Epítome, é particularmente visível na transposição do quinto livro das Instituições Divinas, em que 24 capítulos da obra original são resumidos em somente dois da obra mais recente. Porquê, esta enorme ausência desses temas no Epítome, quando, até pela sua repetição dentro de um mesmo livro, nos poderiam parecer de grande importância? Parece-nos justo concluir que se as Instituições Divinas eram uma obra mais direccionada para um público pagão, a quem importaria fazer ver tudo aquilo que estava incorrecto na sua conduta perante a nova religião, já o Epítome seria dirigido a um outro tipo de público ${ }^{68}$, composto quase exclusivamente por Cristãos e para quem esses mesmos conteúdos fariam muito pouco sentido.

Desse mesmo plano programático é também evidente a selecção de material que é feita dentro de cada capítulo da obra. Se nas Instituições Divinas Lactâncio cita Cícero ${ }^{69}$, as Sibilas e Hermes Trimegisto com

\footnotetext{
${ }^{67}$ Div. Inst. 7.27, Epit. Div. Inst. 73.

${ }^{68}$ A referência inicial ao “irmão Pentádio", bem como a ausência geral de referências - muito patentes na obra original - ao Imperador Constantino I, a essa ideia nos podem conduzir.

${ }^{69}$ Em particular o tratado Da Natureza dos Deuses, mas também textos como o Dos Ofícios e as Disputações Tusculanas.
} 
relativa frequência, no Epítome só menciona o primeiro cinco vezes, dedica um capítulo às segundas (fora do qual apenas são mencionadas seis vezes) e a terceira figura é referida somente quatro vezes. Sendo Cícero um autor cujo saber era profundamente apreciado pelos Pagãos, a profusa citação dos seus trabalhos faria sentido, mas a constância desse elemento na obra principal não se reflecte na versão dedicada a Pentádio, evidentemente cristão e para quem o conhecimento das Escrituras provavelmente seria mais importante do que o dos textos do famoso autor latino.

Já a ausência de referências às Sibilas e a Hermes Trimegisto poderá prender-se com o facto de esses serem lugares-comuns para um cristão, um conjunto de evidências que associadas aos testemunhos dos profetas provavam a divindade de Cristo e a predestinação da mensagem que ele trazia. Se esses elementos seriam de especial importância para introduzir os praticantes de outras religiões aos fundamentos do cristianismo, pouco sentido fariam para aqueles que já praticavam essa religião e que certamente conheceriam, de uma forma geral, esses testemunhos em favor da fé que seguiam.

Uma possível oposição a esta ideia poderia passar pelo facto de vários capítulos do Epítome estarem ilustrados com profusas citações das Escrituras $^{70}$, que o autor até mantém da sua obra original ${ }^{71}$, mas contrastando esses instantes com os capítulos iniciais da obra, em que citações são raras e as alusões a diversos autores pouco comuns ${ }^{72}$, facilmente somos levados a concluir que as copiosas menções do primeiro caso se prenderiam com a necessidade de ter várias referências concretas num só local, enquanto que a raridade das segundas, que muito provavelmente não seriam suficientes para afastar qualquer pagão da sua religião, se deviam à necessidade de aí apresentar somente

\footnotetext{
${ }^{70}$ Epit. Div. Inst. $46 \mathrm{ff}$.

${ }^{71}$ Perrin 1986: 24-25.

${ }^{72}$ Epit. Div. Inst. $3 \mathrm{ff}$.
} 
um esqueleto da argumentação, que depois poderia ser complementado com o recurso a fontes exteriores.

Outro elemento que nasce da comparação de ambas as obras é o facto de o autor mencionar muitas opiniões filosóficas nas Instituições Divinas, mas a elas apenas fazer algumas vagas alusões, muito directas, ao ponto que está a tratar, no Epítome. Novamente, se para um adepto das antigas religiões seria fulcral a apresentação de todos esses dados, já para um cristão bastaria saber que as opiniões deste ou daquele filósofo não concordavam com as Escrituras e os "testemunhos divinos", pelo que só poderiam estar erradas - ideia em que este autor coloca sempre uma importante ênfase.

Além disso, há que ter em conta que o Epítome não foi criado somente através da supressão de conteúdos, até por existirem conteúdos exclusivos ao novo texto, como foi posto a descoberto através da comparação de ambos. Teriam essas alterações surgido na sequência de novas leituras por parte de Lactâncio? Perrin ${ }^{73}$ argumenta a existência de seis paralelismos que nos remetem para a possibilidade de este autor ter, alguns anos após a escrita das Instituições Divinas, lido a obra de Arnóbio de Sica e sido influenciado pelo conteúdo desta na criação do Epítome, mas as evidências que temos não nos chegam para formar uma hipótese dessa potencial ligação. No entanto, é inquestionável que o autor melhorou algumas das suas ideias, em particular ao nível do seu conhecimento do texto bíblico e do cânone cristão, bem como da sua composição ${ }^{74}$. Estas são alterações que, pressupondo a existência de uma nova audiência, nos parecem fazer absoluto sentido, já que todos aqueles que estivessem familiarizados com as problemáticas da nova religião tenderiam a ser muito mais críticos nesses pontos específicos, levando o autor a melhorar a sua criação com base nas opiniões que, muito provavelmente, terá recebido na sequência da publicação dos seus sete livros.

\footnotetext{
${ }^{73}$ Perrin 1984.

${ }^{74}$ Perrin 1986: 29-36.
} 
Finalmente, se o Imperador Constantino, o Grande, a quem parece ser dedicada a obra, de quem Lactâncio era conselheiro e de quem foi tutor de um filho, é mencionado diversas vezes nas Instituições Divinas, tal nunca ocorre no Epítome, sendo essa obra dedicada a um "irmão Pentádio", figura mencionada uma única vez. Nada mais evidente que essa divergência de públicos, já que escrever para um recém-iniciado no cristianismo, mesmo que este se tratasse de um imperador, não seria o mesmo que escrever para um "irmão", sendo o conteúdo de toda a obra adaptado, de uma forma que quase nos recorda as palavras de São Paulo ${ }^{75}$, em consonância com esse público.

Com base em todas estas evidências podemos concluir que, mais do que um mero resumo das Instituições Divinas, o Epítome da obra tem um público-alvo significativamente diferente. Se o primeiro texto tem uma clara função de introduzir os pagãos ao cristianismo, já o segundo parece ter uma utilidade um pouco distinta, tratando-se quase de um simples catecismo que poderia ser usado para, de uma forma muito mais sucinta, apresentar aos cristãos o conteúdo da obra maior, de forma a que estes, talvez até sem lerem os vastos sete livros que a compunham, pudessem usar esses mesmos argumentos na conversão de novos fiéis. Se, nesse sentido, as Instituições Divinas não deixam de ser uma obra de profundo interesse, também seria difícil a comunicação de todos os seus ensinamentos a um público mais vasto, certamente muito menos culto que o imperador e as classes altas da Nova Roma, parecendo ser essa a enorme dificuldade que o autor tenta corrigir com a escrita do seu Epítome.

\footnotetext{
${ }^{75} 1$ Cor., 9: 19-23.
} 


\section{BIBLIOGRAFIA}

Cameron, A. (2013), The Last Pagans of Rome. Oxford.

Fletcher, W. (1913), "Epitome of the Divine Institutes", in A. Roberts (eds.), J. Donaldson (eds.), A. Coxe (eds.), Ante-Nicene Fathers Vol. 7. New York, 224-258.

Fletcher, W. (1913), “The Divine Institutes”, in A. Roberts (eds.), J. Donaldson (eds.), A. Coxe (eds.), Ante-Nicene Fathers Vol. 7. New York.

Lactance, Epitomé des Institutions Divines. Perrin, M. ed. et trad. (1987), SC 335, Paris.

Lactance, Institutions Divines. Monat, P. ed. et trad. (1986-1992), 3 vols., SC 326, 337, 377, Paris.

Perrin, M. (1984), “Lactance lecteur d'Arnobe dans l'Epitome des Institutions?", Revue d'Etudes Augustiniennes 30: 36-41.

Perrin, M. (1986), "L'authenticité lactancienne de l'Épitomédes Institutions Divines: à propos d'un livre récent", Revue d'Etudes Augustiniennes 32: 22-40. 